Recherches politiques internationales sur les espaces issus de l'histoire et de la colonisation portugaises

\title{
Vivendo a nossa ascendência marrana. Ritual e identidades judaicas entre os evangélicos judaizantes no Brasil
}

Embodying Marrano's Roots - Jewish Ritual and Identity among "Judaising Evangelicals" in Brazil

Vivre notre ascendance marrane. Rituel et identité juive parmi les Évangéliques judaisants au Brésil

\section{Manoela Carpenedo}

\section{(2) OpenEdition}

Journals

Edição electrónica

URL: https://journals.openedition.org/lusotopie/4115

ISSN: 1768-3084

Editora

Idemec - UMR 7307

Edição impressa

Data de publição: 1 dezembro 2019

Paginação: 167-191

ISSN: 1257-0273

\section{Refêrencia eletrónica}

Manoela Carpenedo, «Vivendo a nossa ascendência marrana. Ritual e identidades judaicas entre os evangélicos judaizantes no Brasil», Lusotopie [Online], XVIII(2) | 2019, posto online no dia 02 janeiro 2022, consultado o 04 fevereiro 2022. URL: http://journals.openedition.org/lusotopie/4115

Este documento foi criado de forma automática no dia 4 fevereiro 2022.

Lusotopie 


\title{
Vivendo a nossa ascendência marrana. Ritual e identidades judaicas entre os evangélicos judaizantes no Brasil
}

\author{
Embodying Marrano's Roots - Jewish Ritual and Identity among "Judaising \\ Evangelicals" in Brazil \\ Vivre notre ascendance marrane. Rituel et identité juive parmi les Évangéliques \\ judaisants au Brésil
}

Manoela Carpenedo

Enquanto parte do nosso povo é assimilado entre as nações, nós resistimos. Nós estamos aqui neste congresso buscando estreitar a nossa relação com a nossa fé com o nosso Deus. Espero que vocês

estejam tão felizes quanto eu. Escutando as melodias da nossa alma sefardita. É da península ibérica que todos nós viemos. Deus queria que todos nós estivéssemos aqui no Brasil, estamos aqui para celebrar a nossa alma Marrana. Levi, dezembro de 2013

Essa narrativa retirada do meu diário de campo descreve bem as minhas primeiras experiências em um congresso nacional da comunidade evangélica judaizante, objeto deste estudo. A comunidade evangélica judaizante é composta por pessoas com trajetórias carismáticas evangélicas em igrejas pentecostais e Neopentecostais que agora aderem a uma variedade de práticas fortemente inspiradas pelo judaísmo ortodoxo. Motivadas pela rejeição de suas identidades carismáticas evangélicas e pela alusão de uma memória coletiva sefardita ${ }^{1}$ (Carpenedo 2018), essa comunidade adere 
gradualmente a entendimentos rabínicos e incorpora muito dos rituais e das leis religiosas dos Judeus Ortodoxos.

Embora a apropriação de elementos judaicos pelo cristianismo não é nada nova, visto que constitui a própria base da tradição cristã, a corrente apropriação de rituais e narrativas judaicas por parte do cristianismo contemporâneo é uma questão em aberto nos estudos da religião. A literatura corrente acerca do fenômeno foca-se predominantemente em casos localizados no mundo ocidental anglófono, onde a combinação entre discursos judaicos e cristãos normalmente é definida através de duas formas: o Judaísmo Messiânico - que consiste em judeus étnicos que se identificam como seguidores de Jesus - ou o sionismo cristão. Neste último caso, temos cristãos evangélicos que seguem a escatologia dispensacionalista apoiando geopoliticamente $o$ estado de Israel e o papel dos judeus no desenrolar do fim dos tempos. Embora essas categorias sejam extremamente úteis para caracterizar disposições filo-semitas cristãs no contexto anglófono ocidental, elas não são adequadas para entender como o filosemitismo se organiza em outras partes do globo. Para preencher essa lacuna na literatura, entre 2013 e 2015, conduzi uma etnografia em uma congregação evangélica ${ }^{2}$ experienciando um processo dramático de judaização envolvendo a adoção de uma série de rituais e modos de vida semelhantes aos de judeus ortodoxos contemporâneos. Meu objetivo foi compreender os modos pelos quais doutrinas e rituais judaicos estão sendo mobilizados por evangélicos carismáticos no Brasil.

3 Através do meu trabalho de campo, percebi que a identificação de cristãos com o judaísmo é diferente dos exemplos anglófonos ocidentais. Contrastando com os movimentos sionistas cristãos e o judaísmo messiânico, que apesar de suas atitudes filosemitas apresentam crenças e estilos de vida fortemente calcados no cristianismo, esta comunidade em especial está se desconectando gradualmente do cristianismo através do cumprimento das leis mosaicas derivadas da Torah escrita e oral. Para diferenciar estes grupos que estão emergindo no Brasil inspiradas pelo judaísmo ortodoxo de outras tendências filo-semitas no Brasil e no mundo, o termo 'Evangelismo Judaizante' foi criado. A comunidade evangélica judaizante que documentei é a maior deste tipo no país; dividida entre pequenas congregações espalhadas em todas as regiões do país, têm em torno de 8000 a 10000 seguidores, segundo a liderança do movimento. Os membros dessa comunidade são maioritariamente membros da classe trabalhadora e têm em seu passado religioso o envolvimento com igrejas carismáticas evangélicas. Minha etnografia buscou investigar as motivações que levam evangélicos carismáticos sem qualquer background judaico a incorporar os rituais e as modos de vida inspirados pelos judeus ortodoxos, nutrindo, ao mesmo tempo, a crença que Jesus é o Messias esperado.

4 Esse artigo é parte de um estudo maior sobre o fenômeno evangélico judaizante no Brasil. Iniciei minha etnografia em uma comunidade bastante pequena, em torno de 30 pessoas, localizada na área metropolitana de Porto Alegre. A minha conexão com esta comunidade permitiu-me ganhar acesso à sinagoga central, localizada em outra capital da região sul do Brasil, e que conta com mais de 100 membros ativos. Conduzi o meu trabalho de campo em diversas fases entre 2013 e 2015. Minha pesquisa combinou observação participante em serviços religiosos, aulas de hebraico e de costumes judaicos, aulas de dança, programas gravados para o canal da comunidade do youtube, encontros informais e visitas à casa de vários membros da comunidade. Durante a minha participação em congressos, retiros, festas religiosas, experienciei e 
compartilhei refeições e acomodações com as mulheres deste movimento. Essas vivências foram complementadas por uma visita a Israel, coordenada por um líder da comunidade e direcionada à mulheres evangélicas judaizantes. Por duas semanas interagi com esta comunidade de mulheres no lugar considerado mais sagrado do mundo por elas. Após estabelecer uma sólida conexão com a comunidade, selecionei alguns membros para conduzir entrevistas qualitativas. No total, pude compilar mais de 60 horas de narrativas. As entrevistas foram conduzidas com alguns líderes da comunidade e com muitas mulheres participantes do movimento e focaram na experiência religiosa das participantes, suas identidades e, sobretudo, no processo de conversão para o evangelismo judaizante. Todas as entrevistas foram gravadas e transcritas. Todos os nomes referidos aqui são fictícios, afim de proteger a identidade dos participantes.

Durante o curso da minha etnografia, pude observar mikvot (piscinas ritualísticas) serem instalados em quintais, homens, adolescentes e crianças serem circuncidados, comida kosher ser incorporada nas dietas de devotos, mulheres escolhendo respeitar tabus relacionados com a menstruação e adotar padrões estritos de modéstia incluindo a cobertura de seus cabelos com lenços e boinas. Tudo isso sem demonstrar nenhum interesse em serem convertidos ou reconhecidos por instituições judaicas. Pelo contrário, de acordo com a comunidade, seu objetivo maior é o de disseminar a verdade Judaizante para o mundo cristão. Minha pesquisa indicou que a emergência dessas comunidades deve ser entendida como uma renovação religiosa que busca restaurar o evangelismo carismático no Brasil, influenciado particularmente por práticas neopentecostais. Neste contexto, a incorporação de elementos filo-semitas busca tanto reconstruir a autenticidade do cristianismo, como distinguir o grupo de tendências neopentecostais percebidas como moralmente permissivas, materialistas e equivocadas em termos teológicos.

6 Enquanto a incorporação de elementos judaicos visa, sobretudo, restaurar o cristianismo evangélico carismático percebido como degenerado, esta mudança também é motivada por narrativas de uma possível descendência judaica feita através da alusão de identidades Bnei Anussim ${ }^{3}$ /Marranas. Os termos Bnei Anussim ou Marranos referem-se aos judeus sefarditas da península ibérica que foram forçados a se converterem ao cristianismo devido a Inquisição. Algum destes, na virada do século XVII, eventualmente emigraram para o Brasil em busca de prosperidade econômica e mobilidade social (Novinsky 1972; Wachtel 2013; 2001; 2011). Através da mobilização de práticas criptojudaicas e narrativas etno-históricas de uma identidade judaica oculta, meu estudo mostra os modos pelos quais esses evangélicos carismáticos passaram a se identificar gradualmente com o Judaísmo.

7 Dada a forte conexão da comunidade a dogmas e práticas derivadas do Judaísmo ortodoxo, o caso dos evangélicos judaizantes auxilia não somente na teorização de atitudes filo-semitas cristãs, mas também é capaz de explicar a emergência de identidades Marranas no mundo Lusófono do sul global. Além disso, o caso dos evangélicos judaizantes que estudei também contribui para o corpo de estudos sobre identidades Marranas no contexto lusófono (Wachtel 2001, 2011, 2013; Leite 2017; Pignatelli, 2017) e para a emergência do que observadores vêm apontado como Judaísmo periférico.

8 Enquanto a presente literatura é extremamente útil para compreendermos sobre identidades marranas contemporâneas de um ponto de vista etno- histórico e 
microssociológico, a emergência e organização de movimentos coletivos que propõe a aderência de rituais e modos de vida derivados do judaísmo ortodoxo permanece uma questão a ser estudada. Portanto, existe a necessidade de entender a relação entre a performance de rituais e práticas coletivas como meios de se conectar com um possível passado Marrano de forma a nutrir identidades coletivas. Meu estudo sugere que através da incorporação dos rituais e estilos de vida inspirados no judaísmo ortodoxo contemporâneo, os evangélicos judaizantes brasileiros não somente rejeitam o seu passado carismático cristão, mas também reconstroem suas identidades Marranas. No entanto, minha análise indica que não existe uma identificação linear entre os evangélicos judaizantes e as suas identidades judaicas, visto que o processo de incorporação de rituais e práticas judaicas é mediada através de uma constante negociação entre o passado cristão da comunidade e os seus valores derivados do judaísmo.

9 Na primeira parte deste artigo, exploro as razões pelas quais a comunidade rejeitou seu passado carismático cristão a favor das práticas judaicas inspiradas no judaísmo ortodoxo. Subsequentemente, investigo os discursos históricos e o desenvolvimento de identidades marranas no Brasil através do exame de como reminiscências de um suposto passado judaico oculto contribuíram para o dramático processo de judaização deste grupo. Recorrendo a uma análise microssocial, na parte final deste artigo examino como valores judaicos e cristãos são mobilizados na constituição do projeto religioso e ético dos evangélicos judaizantes.

\section{Estabelecendo distância do materialismo e da degeneração moral do pentecostalismo carismático}

10 Análises convencionais da sociologia da religião propõem uma variedade de tipologias para definir a estruturação social de organizações religiosas. Entre as tipologias, temos a seminal dicotomia igreja-seita proposta por Weber (1963) e expandida por Troeltsch (1981). Seguindo esse avanço na literatura, temos o 'continuum' de Niebuhr (1975) que propõe que grupos religiosos se distanciaram gradualmente da organização de seita em direção à igreja. No começo dos anos 1960, com a emergência dos novos movimentos religiosos (New Religious Movements-NRM), outras teorizações passaram a descrever as dinâmicas religiosas. Entre essas tipologias sociológicas, uma em particular é importante para a comunidade em questão. Por exemplo, a tensão entre comunidade religiosa e ambiente social é crucial para definir os contornos dos movimentos religiosos (Stark \& Bainbridge 1985; Wallis 1984). Minha análise indica que um grande tensionamento entre a comunidade e a sociedade emerge como um importante elemento na configuração social dos evangélicos judaizantes. Meu trabalho de campo sugere que a tensão entre o mundo e a comunidade consiste em um importante elemento para entendermos a transformação dramática de valores, crenças e práticas da comunidade evangélica judaizante. De fato, o processo de identificação com o judaísmo promoveu uma dramática rejeição do mundo secular e uma aderência a formas austeras de vida. Neste contexto, prefiro não situar a comunidade em uma categoria tipológica, visto que considero mais produtivo localizar o grupo no que observadores da religião vêm denominando movimentos fundamentalistas de conversão (Almond 2003). 
11 A renovação religiosa dos evangélicos judaizantes busca restaurar o que é visto como a degeneração moral e religiosa do evangelismo carismático brasileiro. De acordo com o grupo, comunidades religiosas, aqui entendidas à luz das contribuições Durkheimianas acerca da origem social do sagrado e da forma pelas quais representações religiosas expressam uma realidade coletiva, devem manter certa distância em relação à sociedade secular. Essa tensão deve ser reforçada através de um modo distinto de vida e de visão de mundo que visa prevenir seus membros a serem engolidos pelo mundo degenerado e pecador. Nesse contexto, evangélicos judaizantes condenam o evangelismo carismático pela sua falta de fronteiras entre o sagrado e o mundano. Uma das participantes da pesquisa explica esta dimensão.

Hoje o crente, ele veste shortinho. Pinta o cabelo. Hoje ser crente não tem nada de diferente. Não tem nenhuma diferença entre o crente e o católico ou até os que estão no mundo.

Ida, 50 anos, conversa informal na sinagoga

12 A comunidade evangélica judaizante com que trabalhei critica veementemente o processo de relaxação moral visto em muitas das igrejas pentecostais, especialmente as neopentecostais (Birman 2007). Para o grupo, a busca pelo sagrado implica um afastamento total da sociedade secular, incluindo igrejas pentecostais. De acordo com a comunidade, igrejas evangélicas carismáticas são fracas e pouco equipadas para reforçar condutas moralmente corretas a seus seguidores.

13 Além da crítica referente às barreiras morais, os evangélicos judaizantes também rejeitam o materialismo encontrado no pentecostalismo, principalmente em relação a teologia da prosperidade. Na teologia da prosperidade, sucesso e riqueza material são prometidos para seus seguidores. A teologia da prosperidade também ensina que a riqueza material depende da capacidade do indivíduo entender as leis espirituais e atuar de acordo com elas. Esses discursos reorientam o indivíduo de modo que a bênção divina é uma porta para o sucesso. A teologia da prosperidade também define que fazer doações para a igreja é uma afirmação e sujeição á Deus. Este processo de libertação permite o indivíduo receber muitas bençãos. A doutrina requer voluptuosas doações para a igreja, de forma que estas possibilitarão graças referentes à saúde e a prosperidade material (Lehmann, 1996; Van Wyk, 2014). A correlação de sacrifício (dar generosamente à igreja) e receber a benção de Deus abre novos horizontes aos membros.

14 A comunidade evangélica judaizante com que trabalhei repudia fortemente essa lógica encontrada principalmente no neopentecostalismo. Curiosamente, essa crítica ecoa dos discursos seculares convencionais. Evangélicos judaizantes afirmam veementemente que pentecostais carismáticos são enganados pelas falsas promessas da teologia da prosperidade. Em uma entrevista com uma das participantes deste estudo, Tziporah revela que o repúdio a esse tipo de doutrina foi uma das razões que a motivaram (ela e seu marido) a escaparem dos ensinamentos falsos sobre prosperidade propagado em uma igreja neopentecostal.

Se eu falar pra ti Manoela tu não vai acreditar. Antes de virar judia eu e o meu marido, a gente era da Universal (Igreja Universal do Reino de Deus). Nós éramos membros por quatro anos. Nesse tempo a gente deu pra eles, tudo que a gente tinha! Eles pegaram tudo! E sabe eu não me considero ignorante, comecei a faculdade (...) no fim a gente deu tudo para eles, nossas economias, nossa caminhonete, até as nossas alianças. tudo!

Tziporah, 35 anos 
Embora alguns membros da comunidade evangélica judaizante confessarem que foram beneficiados pelas suas experiências com a teologia da prosperidade e sua retórica salvação, estes não veem mais o ganho material como uma forma compatível de viver uma vida correta e religiosa. De acordo com essa perspectiva, o poder da fé em prover saúde e bens materiais implica em uma postura infantil de quem é inclinado à 'lavagem cerebral' e à submissão religiosa extrema. A necessidade de pedir por incansáveis 'bendições de Jesus', como uma das minhas participantes de pesquisa coloca, é substituída pelas a centralidade de viver uma fé pura e correta.

Portanto, como vemos, a mudança religiosa desta congregação evangélica judaizante desafia algumas das características preponderantes do evangelicalismo carismático brasileiro, tais como permissividade moral e ênfase em doar para a igreja para atingir recompensas materiais. Através da construção de uma religiosidade caracterizada pela obediência de diversas leis mosaicas, a comunidade constrói um sentido de distinção espiritual, cultural e social de suas identidades carismáticas pentecostais passadas.

\section{Cartografia de discursos históricos: a emergência de identidades Marranas contemporâneas}

Minha análise acerca da mudança dramática dessa comunidade demonstra os modos pelos quais estórias pessoais, desejos religiosos, elementos históricos e até ideologias nacionais estão entrelaçadas nessa renovação evangélica judaizante. Um aspeto central desse movimento religioso refere-se às alusões de uma ascendência Judaica remota. Nesse processo, os evangélicos Judaizantes invocam uma experiência de uma memória coletiva judaica através da lembrança de práticas criptojudaicas de um passado remoto Marrano para justificar a sua incorporação de práticas judaicas e estilos de vida ortodoxos.

Bnei Anussim, Marranos, ou cristãos novos ou simplesmente conversos são uma categoria histórica e legal que define judeus sefarditas ibéricos que foram forçados a se converterem ao judaísmo na virada do século XV na península Ibérica. Apesar de serem forçados a se converterem, muitos desses judeus mantiveram vestígios de sua fé ancestral. Práticas judaicas clandestinas - cripto-judaísmo - desenvolveram-se como uma opção viável para os judeus sefarditas preservarem suas crenças após serem forçados à conversão ao catolicismo. Na virada do século XVII, grande parte dos cristãos novos emigrou de Portugal e Espanha para colônias na América Latina. Muitos desses cristãos novos vieram para o Brasil buscando oportunidades econômicas, mobilidade social e paz (Novinsky 1972; Wachtel 2001).

No Brasil, formaram uma importante parte da população portuguesa do Brasil colonial como mercadores, comerciantes de grosso trato e pequenos empresários. Outros eram médicos, advogados e servidores públicos. Alguns até se tornaram padres. Estima-se que os cristão novos compuseram $10 \%$ dos habitantes do Rio do Janeiro $(200,000)$ entre o século XVII e o século XVIII (Silva, 1995). Outros estudos indicam os que cristãos novos eram $12 \%$ da população de Pernambuco durante o mesmo período (Wiznitzer 1966). A grande densidade de cristãos novos no Brasil colonial e a sua integração socioeconômica não preveniram as garras do poder da Inquisição. Embora a Inquisição nunca tenha sido implementada completamente no Brasil, oficiais faziam visitas à colônia entre os séculos XVI, XVII e XVIII (principalmente em áreas como Pernambuco). 
Por exemplo, no século XIX, $90 \%$ dos perseguidos pela Inquisição eram cristãos novos acusados de praticar o judaísmo. Os prisioneiros eram mandados de volta para Portugal para serem julgados em Lisboa onde eram forçados a participar nos Autos da Fé ou nas passeatas públicas de penitência e humilhação feitas para punir os heréticos e os praticantes do judaísmo. Apesar do poder da Inquisição, o criptojudaísmo e as práticas judaizantes eram bastante comuns no Brasil colonial (Novinsky 1982; Wachtel 2001, 2013). Com medo de serem condenados pela os tribunais da Inquisição, muitos Marranos apresentavam uma identidade religiosa cristã na esfera pública, enquanto mantinham secretamente práticas judaicas na esfera privada. Essas práticas incluíam casamentos endogâmicos, restrições alimentares e o acendimento de velas às Sextafeiras.

20 As histórias dos Marranos também são importantes na construção étnica da identidade nacional brasileira. Muitos historiadores ressaltaram o papel do "sangue judaico" na formação da nacionalidade portuguesa. Neste contexto, houve um intenso esforço em apagar a memória dos cristãos-novos. Mário Sá (1924) afirma: "Por toda parte têm os judeus o conhecimento de serem judeus, em Portugal não o têm. Atravessaram as idades sob a designação de cristãos-novos, e com a perda da unidade religiosa, se foram de si próprios desmemoriado". De forma similar, no Brasil, intelectuais do século XX também debateram sobre os elementos judaicos na identidade brasileira (Lesser 2012). O trabalho seminal de Gilberto Freyre sobre a formação étnica brasileira, 'Casa grande e Senzala' (1986), sugere que 'para o bem ou para o mal' o sangue judaico é um componente da identidade mestiça do Brasil. Junto com outros membros da inteligência brasileira, Freire acreditava na herança Luso-judaica e que esta estava presente na formação da identidade nacional brasileira. Portanto, não é surpreendente que na psique de muitos brasileiros até hoje exista a ideia de uma identidade judaica mestiça sobre o guarda-chuva do sujeito 'árabe- judeu-português-mozarab-tupí-brasileiro' (Lesser 2012:118).

21 No Brasil colonial, a identidade judaica entre os cristãos novos foi gradualmente traduzida em um pertencimento étnico, ao invés de uma experiência religiosa. Certamente, a identidade dos cristão novos foi afetada pela passagem do tempo. Além disso, em uma sociedade como a brasileira extremamente marcada pela hibridização religiosa, algumas práticas associadas ao judaísmo perderam seus significados originais. É nesse contexto de heterogeneidade que o fenômeno dos Marranos emerge: estes que não eram nem cristãos, nem judeus. Alguns grupos desenvolviam práticas criptojudaicas mas outros não. Como Wachtel (2001) sugere, o fenômeno tem que ser entendido com a sua complexidade e diversidade: entre judeus fervorosos, cristãos sinceros, e uma variedade de combinações sincréticas e acomodações entre os dois. $\mathrm{O}$ exaustivo trabalho dos historiadores Anita Novinsky e Nathan Wachtel reforça a noção de uma latente amnésia cultural judaico-brasileira. Esta historiografia tem sublinhado a ideia de uma memória criptojudaica subterrânea, que contribui para o reconhecimento do sangue judaico como um componente da identidade nacional brasileira. A persistência de uma memória judaica clandestina como uma forma milagrosa de resistência cultural sugere que laços de sangue e transmissão cultural têm um grande papel na manutenção da cultura Marrana no Brasil.

No começo dos anos 1960, temos a reemergência dessas mesmas identidades criptojudaicas no Brasil (Topel 2016) e na América do Norte (Jacobs 2002, Kunin 2009a). Entre os anos 1970 e 1990, grupos afirmando um suposto passado criptojudaico se 
espalharam por todas as partes do Brasil. De acordo com o historiador Bruno Feitler, embora a documentação genealógica seja insuficiente para comprovar a origem Sefaradita Marrana dos indivíduos, muitos grupos ainda insistem em afirmar sua origem judaica. Feitler contesta o argumento aceito na literatura que sugere que laços sanguíneos e transmissão cultural vertical explicam a persistência da cultura criptojudaica no Brasil contemporâneo. Nessa crítica, Feitler (2011) argumenta aqui a resiliência das memórias dos Marranos não é resultado de uma romântica transmissão cultural, mas sim produto de influências externas e de circunstâncias históricas experienciadas pelos cristãos novos durante os séculos. Ele sugere que a emergência de grupos invocando suas origens Marranas no século XXI não é determinado pelos preceitos ou práticas ou alguns "costumes vistos como judaicos", mas sim a (re)aparição da identidade Marrana se deve ao trabalho dos historiadores e as pessoas que se autodescrevem criptojudeus. Em outras palavras, a ressurgência das identidades Marranas é o resultado de um contato externo com o judaísmo e com a tradição judaica, através de livros, internet e documentários. Mais do que nunca, influências externas encarnadas no trabalho dos historiadores reproduzindo essas narrativas parecem ser responsáveis pela construção de um imaginário coletivo Marrano.

Contrastando com essa perspectiva conciliatória que enfatiza a continuidade de uma memória judaica subterrânea no Brasil (Wachtel 2001; Novinsky 1982), Topel (2016) e Feitler (2011) questionam porque esses grupos judaizantes estão tão interessados no reconhecimento oficial de sua identidade judaica. De acordo com os pesquisadores, a dependência que esses grupos têm da historiografia e sua exposição a estilos de vida judaicos através da internet indica a fragilidade de suas identidades criptojudaicas. Além disso, a insistência acerca de uma reintegração criptojudaica e de um reconhecimento desses grupos pelo judaísmo tradicional levanta dúvidas sobre a natureza utilitária por trás de seus anseios professados de autenticidade - tais como direitos migratórios (Feitler 2011). Enquanto é possível afirmar que muitos dos grupos que reclamam suas origens Marranas surgidos no Brasil contemporâneo possam sim estar motivados por vantagens instrumentais, eu diria que essa dimensão utilitária que Fleiter reforça não é aplicável a todos os grupos. Por exemplo os evangélicos judaizantes com os quais trabalhei não visavam nenhum reconhecimento da comunidade tradicional judaica que poderia facilitar questões legais como migração a Israel e prestígio social etc.

No entanto, apesar de Topel e Fleiter não embasarem suas observações com material etnográfico substancial, acredito que seus argumentos são bastante convincentes. Meu trabalho entre os evangélicos judaizantes levou à reconsideração do papel que as narrativas históricas têm em motivar 'ressurgimentos étnicos' entre grupos que reclamam as identidades Marranas no Brasil. No entanto, enquanto algumas pessoas afirmam sua descendência judaica somente através de uma imaginação histórica e afirmações sobre o elemento judaico na identidade nacional brasileira, minha análise indica que o material histórico é mais usado para legitimar experiências culturais com o judaísmo do que para justificar um judaísmo ontológico. Aqui não estou afirmando que narrativas históricas não têm uma influência significativa nesse processo; pelo contrário, acredito que elas têm. Minha etnografia indica que o background histórico criptojudaico informa o movimento evangélico judaizante que documentei, visto que pesquisas históricas, livros e documentários sobre os cristãos novos no Brasil são 
frequentemente mencionados como uma das racionalidades motivadoras da transformação religiosa dos evangélicos judaizantes com quem trabalhei.

Por exemplo, uma referência histórica frequentemente mencionada pela comunidade é o documentário 'Estrela oculta do Sertão' (Eiger \& Valente 2005) que explora as memórias de brasileiros descendentes de Marranos através de testemunhos e do trabalho de historiadores como Anita Novinsky e Nathan Wachtel. o documentário foi muito celebrado e constitui uma importante parte da formação cultural de grupos que afirmam sua ascendência Marrana no Brasil. Uma das minhas participantes de pesquisa, originalmente da Bahia, fala sobre a importância desses materiais na reconstituição de seu passado criptojudaico.

Meus avós vivem bem isolados no sertão (..) Eu me lembro que o meu avô costumava orar de uma forma muito diferente. Ninguém conseguia entender o que ele dizia. Eu estou certa que ele tava orando o Shemah ( importante oração no judaísmo), mas ele usava essa coisa que os católicos usam ... o rosário! Outro dia, eu estava lendo Deuteronômio e a minha mãe pulou e disse: essa é a oração que meu pai sempre fazia! Só depois que eu vi o DVD dos Marranos que entendi que essa língua estranha e o que essa oração significava. Eu li alguns livros e fiz algumas pesquisas na internet e eu conectei essas duas coisas. No documentário a gente vê essas senhorinhas nordestinas do Sertão elas são exatamente com a minha avó.

Rebecca, 25 anos, entrevista

Portanto, não estou sugerindo que pesquisadores reproduzem os objetos que estão estudando. 0 marco epistemológico que utilizo considera a separação entre objeto e sujeito frágil e artificial (Haraway 1988). Talvez por isso me sinta tão desconfortável com a insistência em medir níveis de autenticidade judaica destes grupos que afirmam conexões ancestrais com o judaísmo. Na minha opinião, essas tentativas, além de não descrever as realidades sociais vividas por esses grupos, não capturam os modos pelos quais discursos judaicos subterrâneos podem motivar transformações culturais e religiosas. Portanto, ao invés de traçar a legitimidade dessas narrativas Marranas, sugiro que os pesquisadores direcionem seus esforços para compreender os efeitos produtivos que essas narrativas podem ter na vida das pessoas. Considerando essa sugestão, na próxima parte deste artigo explorarei as formas pelas quais as narrativas pessoais e coletivas de um passado Marrano subterrâneo sustenta o movimento de renovação religiosa da comunidade evangélica judaizante em questão. Examinarei como os participantes do movimento apropriam-se de elementos de uma memória coletiva judaica para justificar sua transformação religiosa e ética radical.

\section{Retornando às nossas raízes Marranas}

Durante o meu trabalho de campo, escutei muitas histórias de pessoas e suas conexões com o judaísmo. Participantes do movimento me contaram sobre pesquisas genealógicas sérias e narrativas históricas que demonstram a persistência de fortes costumes criptojudaicos em suas famílias. Eles também narraram suas premonições, sonhos e revelações divinas acerca de seu pertencimento ao povo judeu. Suas histórias desenham memórias vividas que explicitam uma forte conexão com prática judaica. Percebi ao longo do meu trabalho de campo que para muitos evangélicos judaizantes, o processo de recuperar e construir uma identidade Marrana desenvolve um novo relacionamento com as memórias culturais. 
O amor inexplicável por Israel, pelo povo Judeu, as premonições e os sonhos com temática Judaica e, para aqueles com contato direto com práticas criptojudaicas, as orações exóticas escutadas durante a infância e até a pintura da estrela de Davi nas paredes para afastar os espíritos do mal, tudo isso é ressignificado.

$\mathrm{Eu}$ me lembro de ver essa cena quando era pequeno. Eu estava na casa da minha avó, ela estava muito feliz acendendo as velas bem perto da janelas. Hoje eu sei que era para Hanukkah (festa das luzes no calendário judaico). Meu avô chegou em casa depois do trabalho ele viu a toda aquelas velas e ele ficou tão bravo, tão brabo com ela. Ele bateu nela bastante naquele dia. Me lembro que eu não entendi o porquê daquilo. Meu avô era um homem muito bom, muito calmo e não agressivo. Somente hoje consigo entender porque ele fez isso. Ele estava com medo. $\mu$ Jacó, 43 anos, conversa informal na sinagoga

Nessa narrativa podemos ver o alívio de Jacó que finalmente parece entender a reação violenta de seu avô. Na nossa conversa, ele explica que seu avô fez isso para proteger sua família, já que o costume de acender as luzes de Hanukkah poderia causar tensões sociais entre seus vizinhos. A narrativa de Jacó demonstra como pessoas com memória criptojudaicas encontraram em congregações - tais como as dos evangélicos judaizantes que documentei - espaços religiosos e intelectuais para revisitar costumes de família antigos. Entendendo que todas as narrativas que constituem o passado são de alguma maneira imaginadas, essas narrativas são reconstruídas através da apropriação de modelos antigos de uma cultura supostamente ancestral. Em alguns casos, essas memórias são associadas com novos sentidos sociais e culturais e são capazes de autenticar novas práticas religiosas e culturais.

Durante o meu trabalho de campo, encontrei muitas narrativas de pessoas tentando reconstruir suas identidades através de uma possível ascendência judaica. Essas conexões são frequentemente narradas como a última peça de um quebra-cabeça. Esse processo se alinha com que Halbwachs (1925) teoriza sobre mudança cultural. $O$ autor sugere que mudanças culturais são mais facilmente implementadas quando as pessoas reconhecem que certas ideias novas não são inteiramente novas per se, mas constituem uma parte de um passado remoto e têm uma verdade própria.

31 Curiosamente, essas memórias não são estabelecidas de forma individual. Pude observar que a ideia de uma identidade judaica subterrânea é presente de forma mais generalizada entre muito dos evangélicos judaizantes com que trabalhei. Apesar da comunidade evangélica judaizante não distinguir entre membros com backgrounds fortemente criptojudaicos e outros sem raízes judaicas mais explícitas, a comunidade busca expandir coletivamente o escopo de sua ascendência cultural Marrana. Talvez esse seja o motivo pelo qual a comunidade vem crescendo exponencialmente, já que não enfrenta as disputas entre judeus étnicos e gentis que normalmente são vistas em comunidades messiânicas (Cohn-Sherbok 2001; Harris-Shapiro 1999; Kaell 2014).

Para atrair uma vasta legião de seguidores, a comunidade utiliza a estratégia de difundir a identidade Marrana entre toda a população brasileira. Para isso, uma série de estratégias são utilizadas de forma a reforçar tais premissas tais como a internet, genealogias familiares, pesquisa histórica etc. Muitas vezes, os líderes da comunidade conectam nomes e sobrenome de certas famílias a uma ascendência Marrana. Sobrenomes comuns como Silva, Pereira, Lopes, Oliveiras, todos são conectados a uma suposta ascendência judaica. Como um dos participantes dessa pesquisa coloca: "Nós milhões de Oliveiras, Moreiras, Pereiras e outros brasileiros, a gente quer saber o que a gente é. Eu sei que a minha família veio de Portugal e que a gente tem um coração judeu 
por isso que é tudo muito claro para mim no judaísmo (...) a gente quer saber e viver o que a gente realmente é (José, 47 anos).

Além disso, apontando para a herança luso-judaica na formação da identidade nacional brasileira, os líderes religiosos sublinham as origens Marranas dos brasileiros; e isto para promover a ideia de uma conexão genealógica entre a comunidade evangélica judaizante, o povo Judeu e o judaísmo. Portanto, as narrativas acerca de uma identidade judaica subterrânea estruturam o mundo religioso dos evangélicos judaizantes. A comunidade demonstra como identidades bem conhecidas podem ser adaptadas e reapropriadas de acordo com os elementos simbólicos encontrados dentro de certas especificidades sociais e culturais. Ao invocar a figura de um sefardi português judeu convertido à força ao cristianismo, como figura a fundadora, os evangélicos judaizantes se conectam a uma herança judaica, cultural e religiosa.

\section{Aprendendo a ser judeu: incorporando e vivendo a teshuvá}

O caso dos evangélicos judaizantes que estudei indica que memórias históricas da presença Marrana no Brasil, lembranças de práticas criptojudaicas não podem ser entendidas sem considerarmos a transformação religiosa e ética da comunidade, a teshuvá. O termo teshuvá pode ser interpretado de diferentes maneiras. No judaísmo tradicional significa tipicamente o retorno à uma religiosidade estrita baseada no cumprimento das leis mosaicas e nas leis orais. Em hebraico, teshuvá se relaciona ao arrependimento dos pecados, ao retorno das leis divinas e ao retorno ao passado ancestral. 0 termo é amplamente utilizado por grupos de judeus ortodoxos que visam proselitizar judeus seculares que não aderem às leis mosaicas. 0 movimento de teshuvá encabeçado pelo Lubavitch Chassidim (Chabad) é considerado uma característica contemporânea do judaísmo, tanto que este vem reestruturando a cultura e muitas das instituições do judaísmo tradicional.

Inspirado pelo retorno da obediência estrita das leis mosaicas e o retorno às nossas raízes Marranas, por 15 anos a liderança dos evangélicos judaizantes vem introduzindo a prática de muitas leis da Halakha. ${ }^{4}$ Durante o meu trabalho de campo, tive a oportunidade de testemunhar a incorporação gradual dos dogmas e das práticas judaicas em algumas das comunidades dos evangélicos judaizantes no Brasil. Nenhuma dessas mudanças ocorreram abruptamente ou estão totalmente implementadas na comunidade. Por exemplo, a comunidade não observa as leis da Kashrut que requer a separação de carne e de leite. Enquanto o trabalho não é permitido durante o Shabbat, alguns membros usam - com algumas restrições - equipamentos elétricos. No entanto, o sentimento de estar progredindo ano após ano em direção a um modo de vida ortodoxo judaico é uma característica constante do movimento que observei.

Teshuvá entre os evangélicos judaizantes promoveu a construção de de uma cultura religiosa não herdada, informada sobretudo por versões ortodoxas do judaísmo. Como podemos imaginar, essas transformações inauguraram uma mudança dramática na vida de seus seguidores. Práticas corriqueiras da vida cotidiana foram drasticamente alteradas em favor da performance de valores inspirados no judaísmo ortodoxo. Nesse contexto de transformação de regras e valores, essas mudanças implicam que os membros exerçam um grande esforço para cumprir e honrar essas novas demandas 
éticas e culturais. Esta adoção de práticas judaicas se relaciona a um constante esforço ético de trabalho de si.

Nesse contexto, ser judeu não é algo que é herdado, mas sim aprendido. Os evangélicos judaizantes constroem suas identidades através da prática de leis e hábitos inspirados pelo judaísmo. O sermão de Levi é indicativo:

Não é tão simples não é tão simples como cumprir a Torah. Nós devemos pensar como judeu, ter sempre as tradições judaicas na nossa cabeça. Existem dois jeitos de entender a Torah, a Bíblia, o jeito judeu e o jeito errado(!) (...) o jeito de pensar judeu tem que mudar a nossa identidade. Agora temos essa motivação, essa motivação de construir a nossa identidade judaica. Você não deve ser um judeu só no Shabbat. Você tem que ser judeu de domingo a domingo. Você deve recitar as preces da manhã, você deve orar com seu tefillin ${ }^{5}$ e estudar a sua porção diária da Torá. Por exemplo o quando você veste o seu tzitzit, ${ }^{6}$ você vai ver e vai produzir a sua identidade a sua conexão com Deus e com os com os mandamentos.

Levi, sermão na sinagoga

A aderência do repertório cultural judaico tem um grande valor na vida desses antigos carismáticos pentecostais. A experiência de mudança é intensificada e ritualizada, já que muitas formas de devoção agora abundam na vida da comunidade. De manhã à noite, os membros aceitam deliberadamente os numerosos rituais inspirados pelo judaísmo ortodoxo. Através das experiências ricas de "viver a teshuvá", a comunidade performa os seus desejos de pertencimento ao universo judaico, ao mesmo tempo que recria suas experiências com o sagrado. A incorporação de rituais pela comunidade é avidamente discutida pelo grupo de estudos conduzidos por líderes da congregação (Kollel). Nesses encontros, a literatura rabínica é estudada, os comentários de diversos sábios da teologia e jurisdição judaica são debatidos, tais como Rashi e Ramban, tudo à luz da mudança religiosa dos evangélicos judaizantes.

Não restam dúvidas que essas experiências transformaram dramaticamente as identidades religiosas desses antigos evangélicos carismáticos. Teshuvá traz um novo sistema de valores à comunidade. Agora os membros devem embarcar em uma precisão ritualística através de uma religiosidade bastante rígida. Como Levi indica, os evangélicos judaizantes devem ativamente trabalhar em suas transformações éticas. Diferentemente do cristianismo, o judaísmo é mais inclinado a enfatizar o comprimento com as regras religiosas ao invés da teologia per se, sendo uma fé de uma orientação mais prática. Isso significa que para incorporar todas as regras derivadas do judaísmo em seus repertórios culturais, os evangélicos judaizantes devem literalmente "viver a fé".

Neste contexto, toda ação individual, como uma das minhas participantes coloca, pode potencialmente se tornar um ato de reverência e conexão com divino. Como devotos judeus Hassidim, esses antigos evangélicos carismáticos buscam trazer o sagrado em suas vidas diárias através de práticas que visam honrar o cumprimento das leis mosaicas. A performance dessas transformações é descrito por Rivka:

Judaísmo não é que nem ser evangélico. Judaísmo está em tudo que você faz. Ele está presente quando você entra na tua casa (...) A gente tem que beijar a mezuzah. Alguns dos meus vizinhos, eles acham que eu sou louca porque eu tenho que beijar minha porta toda vez que eu entro na minha casa. Como uma mulher judia eu tenho que fazer todos os rituais o dia inteiro. Quando a gente vai comer, a gente tem que tem que consagrar a comida, quando a gente vai para o supermercado a gente tem que ver se o alimento é kosher (...) Então é que nem que nem estar em um ritual 
todo dia, o dia inteiro.

Rivka, 35 anos, entrevista

41 A narrativa de Rivka captura bem a essência prática ritualística do judaísmo. Em seu testemunho ela demonstra a experiência de viver o judaísmo. No entanto, não é somente o caráter prático da religião que essa narrativa expressa. Entender os rituais como formas em que valores culturais são expressos e organizados (Turner, 1970) nos permite ver a mudança religiosa, e que alguns rituais provenientes do judaísmo afeta os sistemas cultural, moral e identitários entre os membros da comunidade estudada.

Outra forma empregada pelos cientistas sociais para avaliar os efeitos transformadores de novas categorias culturais em um contexto social específico é o de examinar o poder que estes têm em alterar arranjos sociais. De fato, pude observar que a teshuvá fabricou enclaves físicos e sociais na vida desses antigos evangélicos carismáticos.

Embora grande parte dos evangélicos judaizantes compartilhem o desejo de viver alienados do mundo secular e da influência liberal, quando comparados com os judeus ortodoxos hassídicos em comunidades como em Stamford Hill em Londres e no Borough Park em New York, sua encapsulação física está bem longe de ser alcançada. Para citar apenas um exemplo, o complexo da sinagoga dos evangélicos judaizantes não oferece fronteiras físicas robustas capazes de proteger seus membros. Embora uma grande parte dos membros estejam concentrados em algumas áreas suburbanas perto da sinagoga, muitos não vivem próximo uns dos outros. Apesar da vida social dos evangélicos judaizantes se dar essencialmente dentro da sinagoga, eles têm, por exemplo, que atender muitos eventos sociais educacionais e religiosos várias vezes por semana e muitos membros continuam envolvidos em contextos seculares particularmente através de seus ofícios e empregos.

No entanto, as demandas religiosas de seus modos de vida guiadas pelos valores das leis mosaicas promoveram uma grande encapsulação social. Embora em muitos casos famílias estendidas passem pelo processo de conversão juntos, a maior parte das pessoas com quem convivi revelou o stress acompanhado pelo afastamento de seus familiares que não se identificam com os preceitos evangélicos judaizantes. Para estes, é muito difícil conciliar as interpretações religiosas divergentes e restrições dietéticas, como o consumo exclusivo de comida kosher. Rachel comenta sobre essas dificuldades e o efeito delas em sua relação com a família estendida:

Manoela: E qual foi a reação de sua família?

Rachel: Bem, eles não aceitaram a minha visão, eles são evangélicos, eles acreditam que a graça elimina todas as regras que nós seguimos (...) Eu e meu marido achamos muito difícil. Nós não queremos convertê-los, só queremos ser respeitados. Eu, meu marido e meus filhos não podemos comer a comida da minha mãe. Visitas de família sempre foram complicadas (...) e no fim eu devo aceitar uma certa distância deles (...).

Rachel, 32 anos, entrevistada em sua casa

Enquanto alguns laços sociais são quebrados, outros são constituídos. Não se deve negligenciar o fato de que, ao se converterem a esta fé judaizante exclusiva, os membros são recebidos em uma comunidade altamente acolhedora. Após a cisão com familiares e outras redes sociais, a congregação emerge como o locus social primário na vida dos convertidos. Portanto, não é ao acaso que a instituição e seus membros estão mutuamente comprometidos e extremamente interdependentes. Além disto, a religiosidade da comunidade precisa reforçar essa relação de corespondência entre instituição e fiéis, visto que requerimentos religiosos como circuncisão, aulas de 
hebraico, acesso a comida kosher são necessários para ambos. 0 encapsulamento social também é reforçado pelas regras estritas sobre o matrimônio: os evangélicos judaizantes não permitem a celebração de uniões entre pessoas fora da comunidade. Assim como os judeus ortodoxos, os jovens são encorajados a se casarem ainda cedo, comumente entre os 18 e 20 anos de idade.

Conforme demonstrado nesta seção, a comunidade evangélica judaizante não apenas abraçou esta nova religiosidade, mas criou um novo ethos e sua identidade própria através dos processos de assimilação à alguns preceitos judaicos. Seus membros, agora, usam roupas diferentes, comem comidas diferentes e criam suas crianças de forma diferente. Porém, como irei demonstrar na próxima seção, isto não significa que elementos evangélicos carismáticos e suas racionalidades foram extinguidas. Hibridismo e negociação cultural caracterizam a emergência das identidades judaizantes evangélicas contemporâneas.

\section{Negociando identidades híbridas "Evangélicas Judaizantes"}

47 Enquanto as vidas e as identidades evangélicas judaizantes são substancialmente impactados pela teshuvá, observei que dentro da comunidade alguns elementos cristãos resistiram e continuam a coexistir dentro das novas vidas dos seguidores. Por exemplo, embora a liturgia evangélica judaizante siga a tradição judaica com poucas menções à figura de Jesus (Yeshua), o Novo Testamento (B'rit Hadashah') continua sendo considerado um livro sagrado e é ocasionalmente estudado por membros da comunidade. Também observei a presença da figura de Yeshua (Jesus) em celebrações de datas importantes (tais como a Páscoa, celebrada sob a rubrica de "O Seder de Yeshua") e outros momentos ritualísticos centrais como a cerimônia de conversão. Estes são apenas alguns exemplos de como os valores simbólicos anteriores são articulados no projeto religioso da comunidade.

o fato de o princípio de 'não negar Yeshua' destacar-se como um dos elementos fundamentais desta comunidade não é mera coincidência. Apesar da figura de Jesus não ocupar um lugar central nos dogmas de suas doutrinas e ser deliberadamente incluído em discursos anti-sincréticos (disseram-me explicitamente "que o Messias não é a encarnação de Deus!", "nós não veneramos Yeshua", e "Yeshua não aboliu a Lei"), a figura de Jesus ainda é um símbolo importante. A regra de não negar Yeshua estabelece uma certa conexão com o passado evangélico da comunidade. Evangélicos judaizantes não precisam renunciar Jesus porque, como me afirmaram, "foi através Dele que eles conheceram a Torá". Observei que, por exemplo, no nível microssocial, a ênfase em Yeshua tem efeito prático como um instrumento de autoasserção dos membros que ainda encontram-se muito enraizados no cristianismo. Em um de seus congressos nacionais, uma mulher de meia-idade confessou que, apesar das mudanças substanciais no seu modo de viver e de suas crenças, ela estava muito feliz que a organização tinha "pelo menos mantido Jesus".

Essa ligação aos símbolos cristãos pode ser vista através do modo que os indivíduos reinterpretam os símbolos religiosos de seu passado em seu processo de aproximação com o judaísmo. Não há dúvidas de que a centralidade das experiências evangélicas carismáticas anteriores é minada pela transformação religiosa da comunidade; porém 
os mesmos elementos religiosos cristãos ocupam um papel significativo no processo de (re)significação religiosa. É importante frisar que ao longo do processo de conversão, o passado evangélico carismático dos membros não é diretamente confrontado nem rejeitado. Em uma conversa com Sara, ela expõe sua opinião sobre o tema:

Eu acredito que é mais uma continuação da minha Fé; é um melhoramento da minha religiosidade. Porque eu ouvia sobre Jerusalém Israel desde que eu era uma menininha. Nós tínhamos a teoria mas nada da prática (...) Por exemplo, eu não sabia que Yeshua era judeu, eu não entendia isso. (...) E agora eu sinto que tudo faz sentido. Para mim é como um quebra-cabeça onde eu consigo ver as peças e como elas encaixam.

Sara, 35 anos, entrevistada em sua casa

Muitas mulheres na comunidade reiteram os sentimentos de Sara: de que estão vivendo uma continuação e um aprimoramento do seu passado evangélico carismático. A surpresa dos membros ao descobrirem algo novo, mas que não é drasticamente diferente, foi mencionado inúmeras vezes como um elemento importante para entender e abraçar a teshuvá evangélica judaizante. Assim como Sara e outros membros da comunidade, as histórias sobre Jerusalém que eles ouviram durante sua juventude cristã instigaram o seu desejo por se tornarem parte da Israel mítica e bíblica. Ao invés de procurarem igrejas evangélicas carismáticas conservadoras, eles desenvolveram um forte interesse pelo antigo Testamento, o qual combinou a busca por coerência teológica entre as regras do antigo Testamento e as práticas cristãs. De acordo com membros da comunidade, a incorporação de práticas judaicas se apresenta como um caminho religioso mais elevado e coerente para os evangélicos judaizantes; é uma forma de fé mais genuína e íntegra, uma forma que é mais próxima de Yeshua do que suas igrejas anteriores. De fato, eles criam uma ponte entre o seu passado religioso e o seu novo entendimento evangélico judaizante por meio da negociação entre o novo e o familiar em sua transformação cultural.

51 Não é difícil identificar uma lógica evangélica específica na adesão dos evangélicos judaizante às práticas inspiradas no judaísmo. Existe uma continuidade clara entre as identidades evangélicas carismáticas anteriores e as novas práticas judaicas. No entanto, essa negociação não é sempre fácil. Uma das minhas informantes descreve seus sentimentos ambíguos sobre suas doutrinas, ensinamentos e práticas passadas:

Foi como se Deus tirasse a venda de meus olhos. Eu era esse tipo de crente que sempre tinha a bíblia em mãos. Foi chocante quando eu percebi que na minha Bíblia evangélica a gente tinha todas as instruções dadas por Deus e que nós estávamos seguindo elas de forma errada por todo esse tempo. Eu não conseguia acreditar nisso.

Sharon, 35 anos, entrevista em sua casa

52 A narrativa de Sharon expressa como os convertidos entendem as novas tradições religiosas através da interpretação de seus recursos evangélicos carismáticos anteriores. Ao mencionar que a "verdade judaizante" sempre estava em sua própria bíblia evangélica, Sharon revela a importância da continuidade entre cristianismo e judaísmo em sua estratégia pessoal de significação. Símbolos de seu passado ainda conectam membros à sua fé cristã anterior; elementos evangélicos cristãos ainda são salientes em seu repertório e coexistem com os novos elementos judaicos. Assim, através do ofuscamento de algumas contradições, da manipulação de recursos simbólicos e religiosos anteriores, e da adoção de novos conceitos religiosos e costumes, os evangélicos judaizantes criaram uma narrativa religiosa que integra suas identidades cristãs anteriores com suas identidade judaizantes emergentes. 


\section{Conclusão}

53 particularidades culturais podem ser engenhosamente ressignificadas em processos de mudança através da combinação de diferentes dogmas religiosos e reinterpretação de práticas anteriores. É interessante que a comunidade evangélica judaizante não apenas invoque identidades judaicas recuperadas do passado, mas também recicle parte de sua dinâmica híbrida. Apesar de reconhecer que as práticas religiosas atuais dos evangélicos judaizantes tem pouca conexão com o passado dos Marranos do Brasil colonial, o projeto híbrido do movimento se relaciona com a dualidade histórica vivida por muitos cristão novos séculos atrás. Mesmo que não intencionalmente, o caráter sincrético do universo Marrano é indiretamente celebrado pelas práticas religiosas híbridas e as ideias da comunidade estudada. Deste modo, talvez a hibridez constitua a conexão de caráter único entre os Marranos do Brasil colonial e os evangélicos judaizantes. tiveram um impacto substantivo no modo que os Marranos transmitiram dogmas religiosos e culturais por gerações. Documentos de arquivos da Inquisição mostram uma intensa bricolagem teológica entre os cristãos novos no Brasil colonial. Registros da Inquisição no Rio de Janeiro (1719) documentando a confissão de cristãos novo demonstram esta faceta religiosa híbrida: "a nova cristã Teresa confessou para o tribunal da Inquisição que ela não reconhece Jesus como Deus, nem a Trindade (...) ela declara que observa a lei de Moisés rezando 'Pai Nosso' e 'Ave Maria' (...) sem modificações. Para Teresa, Jesus é a mesma pessoa que Moisés, que é Deus e filho da Rainha Éster a mãe de Moisés." (Wachtel, 2001: 258-259).

Esses exemplos demonstram que a combinação inusitada das práticas cristãs e judaicas não é, de fato, uma novidade. Hibridização religiosa e cultural marcaram a identidade Bnei Anussim/Marrana desde o início. Desta forma, ao retornar aos costumes judaicos e preservar alguns dos dogmas cristãos, os evangélicos judaizantes estão, contraditoriamente, celebrando o caráter híbrido de suas supostas raízes Marranas. Ao contrário de outros grupos judaizantes que desenvolveram seu próprio processo de construção identitária seguindo exclusivamente linhas judaicas, os evangélicos judaizantes paradoxalmente resgataram uma tradição híbrida, cuja memória coletiva não é apenas judaica, mas mestiça. Isto é, a comunidade evangélica judaizante não abraça cegamente nem emula os recursos judaicos, tampouco se converte ao judaísmo convencional.

Assim, o 'fazer' da identidade entre os evangélicos judaizantes os conecta a uma tradição cultural judaica e toma forma na imagem do judeu Sefardita que foi forçado a se converter ao cristianismo. Sua conversão ecoa a fidelidade à memória coletiva ancestral; é a fé da lembrança a qual Wachtel (2001) se refere. Ao mesmo tempo, a fé dos evangélicos judaizantes não presta homenagem ao passado simplesmente emulando o judaísmo: eles preservam a tradição cristã religiosa e, paradoxalmente, celebram a lógica religiosa híbrida dos Marranos enquanto se mantém o quão fiel possível às suas reminiscências imaginadas. 


\section{BIBLIOGRAFIA}

Almond, G. A. 2003, Strong Religion. The Rise of Fundamentalisms Around the World, Chicago, University of Chicago Press.

Birman, P. 2007, “Conversion from Afro-Brazilian Religions to neo-Pentecostalism: opening new horizons of the possible", in T. Cleary \& E. Steigenga eds., Conversion of a continent: contemporary religious change in Latin America, New Jersey, Rutgers University Press: 115-132.

Carpenedo, M. 2018, "Collective memory in the making of religious change. The case of 'emerging Jews' followers of Jesus", Religion, 48(1): 83-104.

Cohn-Sherbok, D. 2001, Voices of Messianic Judaism. Confronting Critical Issues Facing a Maturing Movement, Baltimore, Lederer Books.

Eiger, E. \& Valente, L. 2005, Estrela Oculta do Sertão, Brazil, Fototema.

Feitler, B. 2011, "Four chapters in the history of crypto-Judaism in Brazil: the case of the northeastern New Christians (17th-21st centuries)", Jewish History, 25(2): 207-227.

Freyre, G. 1986, The Masters and the Slaves. A Study in the Development of Brazilian Civilization, Berkeley, University of California Press.

Halbwachs, M. 1925, Les cadres sociaux de la mémoire, Paris, Bibliothèque de philosophie contemporaine.

Haraway, D. 1988, "Situated Knowledges: The Science Question in Feminism and the Privilege of Partial Perspective”, Feminist Studies, 14(3): 575-599.

Harris-Shapiro, C. 1999, Messianic Judaism. A Rabbi's Journey Through Religious Change in America, Boston, Beacon Press.

Jacobs, J. L. 2002, Hidden Heritage. The Legacy of the Crypto-Jews, Berkeley, University of California Press.

Kaell, H. 2014, “Born-again seeking: explaining the gentile majority in messianic Judaism", Religion, 45(1): 42-65.

Kunin, S. D. 2009, Juggling Identities. Identity and Authenticity among the Crypto-Jews, New York, Columbia University Press.

Lehmann, D. 1996, Struggle for the Spirit. Religious Transformation and Popular Culture in Brazil and Latin America, Cambridge, Polity Press.

Leite, N. 2017, Unorthodox kin. Portuguese Marranos and the Global Search for Belonging, Berkeley, University of California Press.

Lesser, J. 2012, Immigration, Ethnicity, and National Identity in Brazil. 1808 to the Present, Cambridge, Cambridge University Press.

Niebuhr, H. 1975, Social Sources of Denominationalism, New York, New American Library.

Novinsky, A. 1972, Cristãos Novos na Bahia, Sao Paulo, USP.

Novinsky, A. 1982, A Inquisição, Sao Paulo, Brasiliense.

Pignatelli, M. dir. 2017, Judeus e Cristãos Novos no Mundo Lusófono, Lisboa, Colibri. 
Silva, L. G. F. da. 1995, Heréticos e Impuros. A Inquisição e os Cristãos-Novos no Rio de Janeiro, século XVIII, Prefeitura da Cidade do Rio de Janeiro, Secretaria Municipal de Cultura.

Stark, R. \& Bainbridge, W. S. 1979, "Of churches, sects and cults: Preliminary concepts for a theory of religious movements", Journal of Scientific Study of Religion, 18: 117-33.

Topel, M. F. 2016, “Judaism Revivals in Brazil”, in Schmidt, B. \& S. Engler eds., Handbook of Contemporary Religions in Brazil, Leyden, Brill: 253-266.

Troeltsch, E. 1981, The social teaching of the Christian churches, Chicago, University of Chicago Press.

Turner, V. 1970, The Forest of Symbols. Aspects of Ndembu Ritual, Ithaca, Cornell University Press.

Van Wyk, I. 2014, The Universal Church of the Kingdom of God in South Africa a Church of Strangers, Cambridge, Cambridge University Press.

Wachtel, N. 2001, La Foi du souvenir. Labyrinthes marranes, Paris, Seuil.

Wachtel, N. 2011, Mémoires Marranes. Itinéraires dans le sertão du Nordeste brésilien, Paris, Seuil.

Wachtel, N. 2013, Entre Moïse et Jésus. Études marranes. XV $-X X I^{e}$ siècle, Paris, CNRS.

Wallis, R. 1984, The Elementary Forms of the New Religious Life, London, Routledge \& Kegan Paul.

Weber, W. 1963, The Sociology of Religion, Boston, Beacon Press.

Wiznitzer, A. 1966, Os Judeus no Brasil Colonial, São Paulo, Pioneira.

\section{NOTAS}

1. Referente aos judeus sefarditas, comunidades que chegaram à península ibérica (Sefarad) durante a segunda diáspora $(70 \mathrm{BC})$ por causa da invasão romana na Judéia e Jerusalém.

2. Visando a preservar a comunidade deste estudo, refiro-me a essa organização somente como Evangélica Judaizante.

3. Em hebraico, "os filhos dos convertidos forçados".

4. $O$ conjunto de leis provenientes da torah escrita e oral.

5. São duas caixinhas de couro, dentro das quais está contido um pergaminho com quatro trechos da Torah. Os artefatos são utilizados por homens religiosos para as suas preces matinais.

6. São franjas ritualísticas utilizadas diariamente por homens religiosos.

7. A Nova Aliança referida pelos membros da comunidade.

\section{RESUMOS}

Baseada em uma etnografia conduzida entre 2013 e 2015, este estudo explora como uma comunidade Evangélica carismática desenvolveu um processo radical de judaização. Enquanto tal processo visa restaurar algumas práticas e teologias cristãs vistas como degeneradas, tal mudança é também motivada por alegações de uma origem criptojudaica reivindicada através de identidades marranas. Através da incorporação de práticas religiosas inspiradas no Judaísmo Ortodoxo, a comunidade coletivamente reconstrói suas identidades 'evangélicas judaizantes'. No 
entanto, a identificação dessa comunidade com o Judaísmo não é linear, mas pautada em uma constante negociação entre elementos judaicos e o passado cristão.

Based on an ethnography conducted between 2013 and 2015, this article explores how a former Charismatic Evangelical community has developed a dramatic Judaizing process in Brazil. While this transformation seeks to restore some Christian understandings and practices deemed as 'degenerated', the community's shift is also motivated by claims of a recovered Jewish descent through Bnei Anussim identities. By embodying religious observance inspired by Jewish Orthodoxy the community collectively reconstructs their Marrano's identities. However, rather than a linear identification with Judaism, the community negotiate their radical Judaising process with elements of their Christian past.

À partir d'une ethnographie conduite entre 2013 et 2015, cet article décrit le processus de conversion au judaïsme d'une communauté évangélique charismatique au Brésil. Alors que cette transformation recherche à restaurer des interprétations et des pratiques chrétiennes jugées comme dégénérées, le tournant de la communauté est également motivé par une revendication d'une ascendance juive à travers l'identité Bnei Anussim. En incorporant les pratiques rituelles inspires de l'orthodoxie juive, la communauté reconstruit collectivement son identité marrane. Cependant, il ne s'agit d'une identification linéaire, puisqu'on assiste dans ce cas à une négociation entre les éléments rituels issus du monde juif et ceux issus du passé chrétien des membres de la communauté

\section{ÍNDICE}

Palavras-chave: evangélicos judaizantes, Bnei Anussim, mudança cultural, Filo-semitismo cristão, evangélicos, Brasil

Keywords: Judaizing Evangelicals, Marranos, cultural change, Christian Philo-Semitism, Charismatic Evangelicals, Brazil

Mots-clés: évangéliques judaisants, marranes, changement culturel, philosémitisme chrétien, évangéliques charismatiques, Brésil

\section{AUTOR}

\section{MANOELA CARPENEDO}

University of Kent, School of European Culture and Languages

m.carpenedo[at]kent.ac.uk 